\title{
Tai Chi as a Therapy of Traditional Chinese Medicine on Reducing Blood Pressure: A Systematic Review of Randomized Controlled Trials
}

\author{
Xiandu Pan $\left(\mathbb{D},{ }^{1,2}\right.$ Li Tian $\left(\mathbb{D},{ }^{1,2}\right.$ Fan Yang $\mathbb{D}^{2},{ }^{2}$ Jiahao Sun $\mathbb{D}^{1,2}$ Xinye Li ${ }^{1},{ }^{2}$ Na An $\left(\mathbb{D},{ }^{3}\right.$

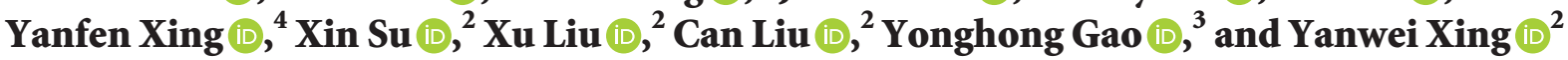 \\ ${ }^{1}$ Beijing University of Chinese Medicine, Beijing, China \\ ${ }^{2}$ Guang'anmen Hospital, Chinese Academy of Chinese Medical Sciences, Beijing, China \\ ${ }^{3}$ Key Laboratory of Chinese Internal Medicine of the Ministry of Education, \\ Dongzhimen Hospital Affiliated to Beijing University of Chinese Medicine, Beijing, China \\ ${ }^{4}$ Shanxi University of Chinese Medicine, Jinzhong 030619, China
}

Correspondence should be addressed to Yonghong Gao; gaoyh7088@163.com and Yanwei Xing; xingyanwei12345@163.com

Received 31 May 2021; Accepted 16 August 2021; Published 6 September 2021

Academic Editor: Hong Chang

Copyright (C) 2021 Xiandu Pan et al. This is an open access article distributed under the Creative Commons Attribution License, which permits unrestricted use, distribution, and reproduction in any medium, provided the original work is properly cited.

Objective. This study systematically evaluated the effects of Tai Chi exercise on blood pressure, body mass index (BMI), and quality of life (QOL) in patients with hypertension. A meta-analysis was performed to provide a reliable reference for clinical practice. Methods. We searched for randomized controlled trials (RCTs) in five English databases and two Chinese databases, with the earliest data dated December 5, 2020. A quality assessment of the methods and a meta-analysis were also conducted. Results. The meta-analysis of 24 studies showed that the intervention group showed better outcomes in terms of systolic blood pressure (SBP) (SMD $-1.05,95 \%$ CI -1.44 to $-0.67, P \leq 0.001 ; I^{2}=93.7 \%$ ), diastolic blood pressure (DBP) (SMD $-0.91,95 \%$ CI -1.24 to -0.58 , $P \leq 0.001 ; I^{2}=91.9 \%$ ), and QOL (physical functioning (SMD $0.86,95 \%$ CI 0.36 to $1.37, P=0.001 ; I^{2}=91.3 \%$ ), role-physical (SMD $0.86,95 \%$ CI 0.61 to $1.11, P \leq 0.001 ; I^{2}=65 \%$ ), general health (SMD $0.75,95 \%$ CI 0.32 to $1.17, P=0.001 ; I^{2}=88.1 \%$ ), bodily pain (SMD $0.65,95 \%$ CI 0.29 to $1.00, P \leq 0.001 ; I^{2}=83.1 \%$ ), vitality (SMD $0.71,95 \%$ CI 0.34 to $1.07, P \leq 0.001 ; I^{2}=84.3 \%$ ), social functioning (SMD 0.63, 95\% CI 0.07 to $1.19, P=0.027 ; I^{2}=93.1 \%$ ), role-emotional (SMD 0.64, 95\% CI 0.22 to $1.06, P=0.003$; $I^{2}=88.1 \%$ ), and mental health (SMD $0.73,95 \%$ CI 0.31 to $\left.1.16, P=0.001 ; I^{2}=88.2 \%\right)$ ) compared to those of the control group. However, no significant improvements were seen in BMI of the intervention group (SMD $-0.08,95 \% \mathrm{CI}-0.35$ to $-0.19, P=0.554$; $I^{2}=69.4 \%$ ) compared to that of the control group. Conclusion. Tai Chi is an effective intervention to improve SBP and DBP in patients with essential hypertension.

\section{Introduction}

Elevated blood pressure is the leading contributor to the global burden of disease and mortality, causing 10.7 million deaths annually $[1,2]$. Globally, about a quarter of adults have hypertension, with 874 million adults having SBP greater than or equal to $140 \mathrm{mmHg}$ [1]. For different reasons, chronic peripheral arteriole spasm for a long time leads to a rise in blood pressure. Persistent hypertension can change the structure of the systemic arterioles and cause pathological changes in the aorta, heart, kidney, and brain.
Pharmacotherapy is mainly used in clinical settings, but this is not recommended for prehypertension patients. Therefore, nondrug treatments of hypertension are worth discussing. Like diet, lifestyle, health education, and other factors, exercise intervention can also appositively affect the treatment of hypertension. Tai Chi is a gentle, safe, and uncomplicated comprehensive exercise, which encompasses the concept of organic wholeness in traditional Chinese medicine and can help regulate body homeostasis and build up a good physique [3]. There have been a number of studies displaying the improvement of Tai Chi in eliciting SBP and 
DBP reductions [4-23]. Moreover, numerous health benefits of Tai Chi have been found; it may ameliorate symptoms, enhance the QOL, regulate physiological mechanisms, and postpone the senility [24-27].

The existing meta-analyses of studies on Tai Chi intervention for hypertension are of low quality since the included literature had relatively short durations of Tai Chi intervention, and none of the meta-analyses included RCTs. In addition, the number of RCTs on Tai Chi intervention for hypertension has increased over the past few years, with two even showing negative results. Therefore, we conducted a systematic review and meta-analysis of RCTs involving Tai Chi as an intervention for hypertension.

\section{Materials and Methods}

2.1. Eligibility Criteria. There were several criteria for inclusion: (1) Tai Chi or Tai Chi with antihypertensive drugs (AHD) or health education (HE) were used as interventions in RCT; (2) participants with primary hypertension defined according to the 2010 Chinese guidelines for the management of hypertension [28] and the 1999 WHO-International Society of Hypertension Guidelines for the Management of Hypertension [29] were included, and the selection criteria were independent of gender, race, or age-based limitations; (3) the results of the trial contained two types of data: SBP and DBP; and (4) languages were limited to Chinese, Korean, and English.

2.2. Exclusion Criteria. The following studies were excluded from the analysis: (1) studies with Tai Chi intervention time of fewer than three months, (2) studies with intervention measures involving traditional Chinese medicine, (3) studies that were literature reviews, and (4) studies with incorrect, incomplete, or invalid data.

2.3. Outcomes. The primary outcomes included SBP and $\mathrm{DBP}$, while BMI and QOL were the secondary outcomes.

2.4. Search Strategy. With a time limit of December 5, 2020, we searched for RCTs in five English and two Chinese databases (Web of Science, PubMed, Korea Citation Index, EMBASE, the Cochrane Library, China National Knowledge Infrastructure, and Wanfang Data). We searched for terms related to Tai Chi and hypertension, namely, "Tai Ji” OR "Tai Chi” OR “Chi, Tai” OR “Tai Chi Chuan” OR “Ji Quan, Tai” OR “Quan, Tai Ji” OR “Taiji” OR “Taijiquan” OR “Taiji” OR "Tai Ji Quan," and "Hypertension" OR "high blood pressure" OR “Blood Pressure, High” OR "blood pressure.”

2.5. Study Selection and Data Extraction. Two investigators ( $\mathrm{XDP}$ and LT) independently screened the literature and extracted studies based on the inclusion and exclusion criteria. Disagreements were resolved through negotiations. The collected information included the following: (1) basic data of the study (title, author, and publication date); (2) basic information of patients, such as age and number of patients included, (3) intervention measures of the treatment and control groups, (4) outcome index data, and (5) possible bias.

2.6. Quality Assessment and Publication Bias. In line with the Cochrane Handbook for Systematic Reviews of Interventions Version 6.1 [30], two investigators independently evaluated the included studies for risk of bias and distinguished their risk levels, including selection bias, performance bias, detection bias, attrition bias, reporting bias, and other biases. For publication bias, the funnel plot test and Egger's regression test were used for evaluation.

2.7. Statistical Analysis. The data were sorted and summarized using Excel, and Stata 16.0 2019 was used for data processing, such as heterogeneity testing, data merging, forest map, and funnel plot creation. The statistics of continuous variables are presented as standardized mean differences (SMD) and 95\% confidence intervals (CI). Heterogeneity was tested using a chi-squared test and $I^{2}$ statistic. In a Cochrane systematic review, as long as $I^{2}$ is less than $50 \%$, its heterogeneity is acceptable, and a fixed effects model should be selected for meta-analysis. Meanwhile, a randomized effect model should be utilized when heterogeneity between studies is significant. Subgroup analysis, meta-regression, and influence analysis were used to manage heterogeneity. If the source of heterogeneity was not found in the subgroup and meta-regression analyses, influence analysis was conducted.

\section{Results}

3.1. Search Strategy and Study Characteristics. We identified 242 studies using the predefined search terms. In addition, 77 duplicated studies were eliminated. Based on the exclusion criteria, we excluded 118 irrelevant studies and obtained 47 potentially qualified studies upon scanning the title and abstract, 23 of which were eventually excluded when the full texts were read. Ultimately, we obtained 24 relevant RCTs for this study (Figure 1).

Overall, the 24 RCTs [4-27] included 2,095 patients, with 1,074 in the treatment group and 1,021 in the control group, as given in Table 1 and Supplementary Table 1. The intervention design included Tai Chi exercise alone or with the intake of $\mathrm{AHD}$ and $\mathrm{HE}$ as interventions. Meanwhile, the control group was no treatment in twelve studies. In three studies, the control groups performed moderate aerobic exercise (AE) without Tai Chi. For both the intervention and control groups, four studies conducted $\mathrm{HE}$ for patients. Regular AHD was prescribed in five studies in both the intervention and control groups. Each study intervention period ranged from 3 months to 5 years, and the outcome indicators included SBP and DBP ( $\mathrm{mmHg})$.

3.2. Quality Assessment and Publication Bias. As shown in Figure 2, six studies $[4,5,7,11,25,27]$ described the generation of random sequences and were considered to be 


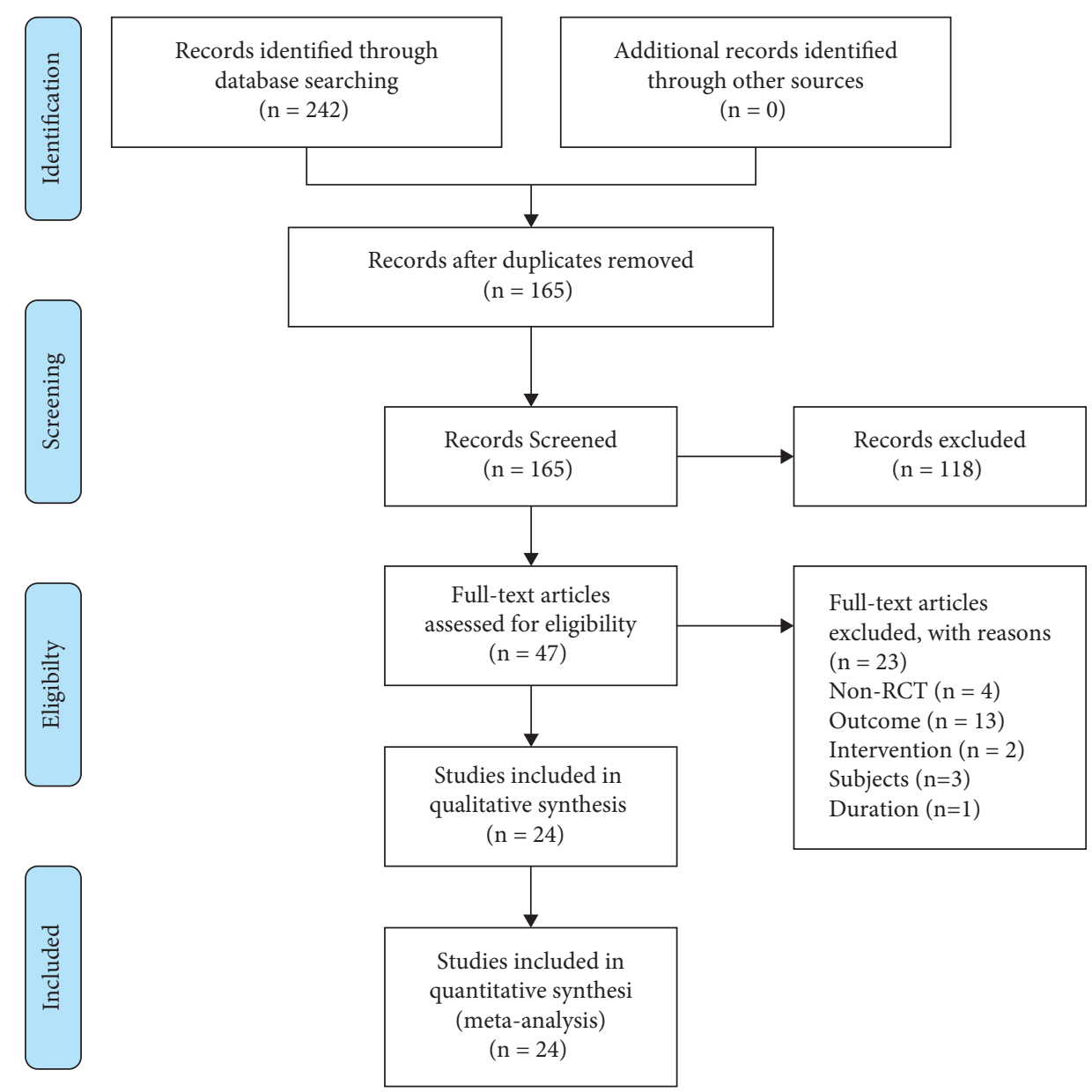

FIgURE 1: Flow diagram of the study selection process.

of low risk. The remaining studies did not describe the generation of random sequences in detail and were judged to have an unclear risk. Three studies $[5,7,25]$ reported allocation concealment and were determined to be of low risk, while the studies that did not report this were considered to have unclear risks. None of the studies blinded the participants and were therefore considered to have a high risk. Two studies $[7,10]$ reported blinding the outcome evaluators and were judged to be at low risk. None of the participants in ten studies $[4,6,8,11-13,15,18,20,23]$ were dropped out. In seven of these studies $[5,7,10,17,22,25,26]$ with dropouts, the numbers and reasons for dropping out were provided and were considered to have a low risk. The remaining studies did not mention withdrawal and were therefore considered to be at high risk. All studies reported their stated outcomes and were judged to have a low risk. We found no other bias.

Funnel plots and Egger's regression tests were used to evaluate for publication bias. The SBP funnel plot (Figure 3(a)) showed that the studies could not form a leftright symmetrical distribution, indicating publication bias in these studies. However, Egger's regression test of publication bias of SBP $(t=-1.52, P=0.143>0.05$; Table 2$)$ indicated no evidence of publication bias. The DBP funnel plot (Figure 3(b)) showed that a distribution with left and right symmetries could not be formed. Egger's regression test of publication bias for $\operatorname{DBP}(t=-2.22, P=0.037$; Table 2$)$ indicated significant publication bias. In addition, the funnel plot asymmetry may be due to the low-quality experiments with poor methodological design, imprecise data analysis, false-positive results, and small sample sizes.

\subsection{Primary Outcomes}

3.3.1. SBP. The results of the meta-analysis of 24 studies that examined SBP indicators (Figure 4(a)) showed that Tai Chi lowered the SBP of participants compared with that of the control group participants (SMD: -1.05 , 95\% CI: -1.44 , $-0.67, P \leq 0.001$; Table 3 ). However, the meta-analysis results showed a statistically significant heterogeneity $\left(I^{2}=93.7 \%, P \leq 0.001\right.$; Figure $\left.4(\mathrm{a})\right)$. Therefore, the source of the heterogeneity should be further discussed.

The difference in the effect of Tai Chi on SBP in patients with high blood pressure may be affected by the intervention measures; therefore, the subgroup analysis was performed (Figure 4(b)) using a random response mode meta-analysis. The subgroup analysis showed that Tai Chi + AHD intervention had no statistical significance $(P=0.314>0.05$; $\left.I^{2}=96.3 \%\right)$, and the SMD after intervention with Tai Chi + HE (SMD -1.79, 95\% CI -2.94 to $-0.64, P=0.002$; 
TABLE 1: Basic characteristics of the included trials.

\begin{tabular}{|c|c|c|c|c|c|c|c|c|}
\hline Study & Year & $\begin{array}{l}\text { Sample } \\
(\mathrm{T} / \mathrm{C})\end{array}$ & Age & Intervention & Control & Duration & Frequency & Outcome \\
\hline $\begin{array}{l}\text { Wang and } \\
\text { Ye }\end{array}$ & 2019 & $50 / 50$ & $60-80$ & $\begin{array}{c}\text { Tai } \\
\text { Chi }+ \text { AHD }\end{array}$ & AHD & $3 \mathrm{M}$ & $\begin{array}{c}3 \text { times per week for } \\
40-60 \mathrm{~min}\end{array}$ & (1) \\
\hline Chan et al. & 2018 & $69 / 62$ & $30-91$ & Tai Chi & $\begin{array}{l}\text { No } \\
\text { treatment }\end{array}$ & $9 \mathrm{M}$ & $\begin{array}{l}\text { At least } 5 \text { times per week } \\
\text { for } 30 \mathrm{~min}\end{array}$ & (1) \\
\hline Liu et al. & 2018 & $35 / 35$ & $\mathrm{I}: 62.4 \pm 2.4 \mathrm{C}: 63.1 \pm 2.1$ & $\begin{array}{c}\text { Tai } \\
\text { Chi + AHD }\end{array}$ & AHD & $6 \mathrm{M}$ & Once a day for $40-60 \mathrm{~min}$ & (1)(5) \\
\hline Ma et al. & 2018 & $55 / 58$ & 60 or over & Tai Chi $+\mathrm{HE}$ & $\mathrm{HE}$ & $24 \mathrm{~W}$ & $\begin{array}{c}3-5 \text { times per week for at } \\
\text { least } 60 \mathrm{~min}\end{array}$ & (1) (2) (3) (5) \\
\hline Shou et al. & 2018 & $98 / 100$ & $18-60$ & Tai Chi & $\begin{array}{c}\text { No } \\
\text { treatment }\end{array}$ & $3 \mathrm{M}$ & Once a day for $20-30 \mathrm{~min}$ & (1) (2) (5) \\
\hline Xiao et al. & 2018 & $42 / 42$ & $\mathrm{I}: 60.2 \pm 4.6 \mathrm{C}: 60.5 \pm 4.9$ & Tai Chi & $\mathrm{AE}$ & $3 \mathrm{M}$ & 5 times per week for $60 \mathrm{~min}$ & (1)(4) (5) \\
\hline $\begin{array}{l}\text { Shi and } \\
\text { Mao }\end{array}$ & 2017 & $30 / 30$ & $30-55$ & Tai Chi + HE & HE & $3 \mathrm{M}$ & $\begin{array}{l}4-5 \text { times per week for } \\
30 \mathrm{~min}\end{array}$ & (1) \\
\hline Zhang & 2017 & $36 / 37$ & $60-80$ & Tai Chi & $\mathrm{AE}$ & $12 \mathrm{~W}$ & 3 times per week for $60 \mathrm{~min}$ & (1) (2) \\
\hline Kim et al. & 2016 & $20 / 20$ & $\begin{array}{c}\mathrm{I}: 73.70 \pm 1.69 \mathrm{C}: \\
73.20 \pm 1.61\end{array}$ & Tai Chi $+\mathrm{HE}$ & $\mathrm{HE}$ & $24 \mathrm{~W}$ & $\begin{array}{c}3-5 \text { times per week for } \\
45 \mathrm{~min}\end{array}$ & (1) \\
\hline Qi et al. & 2015 & $30 / 30$ & NA & Tai Chi & $\begin{array}{l}\text { No } \\
\text { treatment }\end{array}$ & $12 \mathrm{~W}$ & 5 times per week for $60 \mathrm{~min}$ & (1) \\
\hline $\begin{array}{l}\text { Sun and } \\
\text { Buys }\end{array}$ & 2015 & $136 / 130$ & $45-80$ & Tai Chi & $\begin{array}{l}\text { No } \\
\text { treatment }\end{array}$ & $1 \mathrm{Y}$ & $5 \mathrm{~h}$ per week & (1) (2) (3) (5) \\
\hline Wei et al. & 2015 & $42 / 42$ & $\mathrm{I}: 72 \pm 5.56 \mathrm{C}: 70 \pm 6.08$ & Tai Chi + HE & HE & $1 \mathrm{Y}$ & Once a day for $30-45 \mathrm{~min}$ & (1) \\
\hline $\begin{array}{l}\text { Zheng } \\
\text { et al. }\end{array}$ & 2015 & $49 / 49$ & $\begin{array}{c}\mathrm{I}: 54.71 \pm 5.43 \mathrm{C}: \\
55.77 \pm 6.24\end{array}$ & $\begin{array}{c}\text { Tai } \\
\text { Chi + AHD }\end{array}$ & AHD & $12 \mathrm{~W}$ & $\begin{array}{l}4-8 \text { times per week for } \\
40-60 \mathrm{~min}\end{array}$ & (1) \\
\hline Kim et al. & 2014 & $12 / 12$ & I:78.8 \pm 5.4 C:76.2 \pm 4.6 & Tai Chi & $\begin{array}{l}\text { No } \\
\text { treatment }\end{array}$ & $12 \mathrm{~W}$ & $\begin{array}{c}3 \text { times per week for } \\
120 \mathrm{~min}\end{array}$ & (1) \\
\hline Xie and Bai & 2014 & $25 / 25$ & $60-70$ & Tai Chi & $\begin{array}{l}\text { No } \\
\text { treatment }\end{array}$ & $12 \mathrm{~W}$ & 5 times per week for $1 \mathrm{~h}$ & (1) (4) \\
\hline $\begin{array}{l}\text { Chen and } \\
\text { Lu }\end{array}$ & 2013 & $50 / 18$ & $30-82$ & Tai Chi & $\begin{array}{l}\text { No } \\
\text { treatment }\end{array}$ & $12 \mathrm{~W}$ & 6 times per week for $30 \mathrm{~min}$ & (1) \\
\hline Wang et al. & 2011 & $30 / 30$ & $50-70$ & Tai Chi & $\begin{array}{l}\text { No } \\
\text { treatment }\end{array}$ & $16 \mathrm{~W}$ & 5 times per week for $60 \mathrm{~min}$ & (1) \\
\hline Han et al. & 2010 & $30 / 28$ & $62.21 \pm 10.51$ & $\begin{array}{c}\text { Tai } \\
\text { Chi + AHD }\end{array}$ & AHD & $5 \mathrm{Y}$ & Once a day for $45-60 \mathrm{~min}$ & (1) (5) \\
\hline Sun & 2010 & $32 / 32$ & $40-70$ & Tai Chi & $\begin{array}{l}\text { No } \\
\text { treatment }\end{array}$ & $3 \mathrm{M}$ & 6 times per week for $90 \mathrm{~min}$ & (1) (5) \\
\hline Tang & 2008 & $32 / 32$ & $60-70$ & Tai Chi & $\begin{array}{l}\text { No } \\
\text { treatment }\end{array}$ & $12 \mathrm{M}$ & 5-7 times per week for $1 \mathrm{~h}$ & (1) (2) (3) \\
\hline Zhou & 2007 & $60 / 60$ & $\begin{array}{l}\mathrm{I}: 52.3 \pm 10.7 ; \mathrm{C}: \\
53.4 \pm 11.2\end{array}$ & Tai Chi & $\begin{array}{l}\text { No } \\
\text { treatment }\end{array}$ & $12 \mathrm{~W}$ & 6 times per week for $60 \mathrm{~min}$ & (1) \\
\hline Luo & 2006 & $44 / 42$ & $\begin{array}{l}\mathrm{I}: 44.75 \pm 12.10 ; \mathrm{C}: \\
\quad 44.86 \pm 13.05\end{array}$ & $\begin{array}{c}\text { Tai } \\
\text { Chi + AHD }\end{array}$ & AHD & $6 \mathrm{M}$ & Once a day for $45 \mathrm{~min}$ & (1) \\
\hline Tsai et al. & 2003 & $37 / 39$ & $\begin{array}{c}\text { I: } 51.6 \pm 16.3 \mathrm{C}: \\
50.5 \pm 9.8\end{array}$ & Tai Chi & $\begin{array}{l}\text { No } \\
\text { treatment }\end{array}$ & $12 \mathrm{~W}$ & 3 times per week for $50 \mathrm{~min}$ & (1) (2) \\
\hline $\begin{array}{l}\text { Young } \\
\text { et al. }\end{array}$ & 1999 & $30 / 30$ & $60-80$ & Tai Chi & $\mathrm{AE}$ & $12 \mathrm{~W}$ & $\begin{array}{l}\text { 4-5 times per week for } \\
30-45 \mathrm{~min}\end{array}$ & (1) \\
\hline
\end{tabular}

AHD, antihypertensive drugs; HE, health education; AE, aerobic exercise; SBP, systolic blood pressure; DBP, diastolic blood pressure; BMI, body mass index; WC, waist circumference; NO, nitric oxide content; I, intervention group; C, control group. (1), SBP and DBP; (2), BMI; (3), WC; (4), NO; (5), quality of life.

$\left.I^{2}=94.0 \%\right)$ was higher than those with Tai Chi + AHD (SMD $-0.56,95 \%$ CI -1.65 to $\left.0.53, P=0.314>0.05 ; I^{2}=96.3 \%\right)$ and Tai Chi only (SMD $-1.19,95 \%$ CI -1.66 to -0.72 , $P \leq 0.001 ; I^{2}=92.1 \%$ ) (Table 3 ). Three studies compared SBP of the Tai Chi group with that of the AE group, and results showed that there is no significant reduction of SBP in the Tai Chi group compared with the AE group (SMD -0.40, $95 \%$ CI -1.62 to $\left.0.81, P=0.513>0.05 ; I^{2}=94.5 \%\right)$.

Due to the differences in research characteristics, such as subject source, research quality, and intervention cycle, a multivariate meta-regression analysis was conducted with different research characteristics as covariables to explore the sources of heterogeneity. This analysis showed that the source of research objects $(t=0.44, P=0.666>0.05)$, research quality $(t=0.78, P=0.446>0.05)$, and intervention cycle $(t=0.44, P=0.667>0.05)$ as covariant quantities could not explain the interstitial heterogeneity (Supplementary Table 2).

Furthermore, an influence analysis of the individual studies was conducted (Supplementary Figure 1A). The 


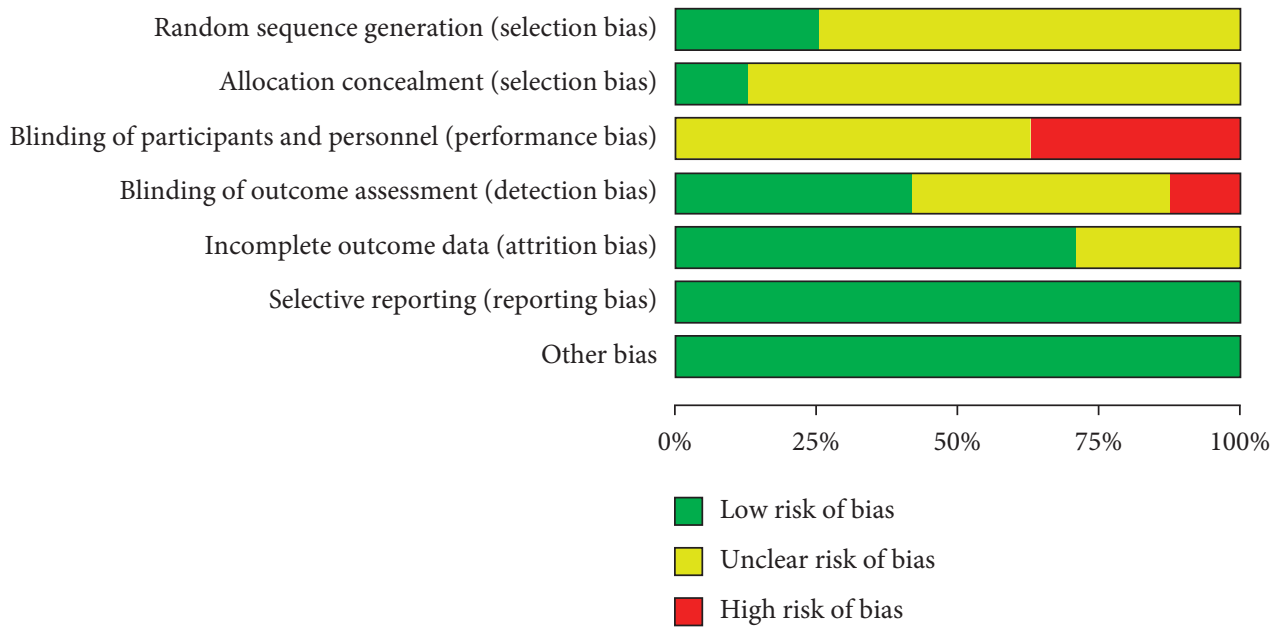

(a)

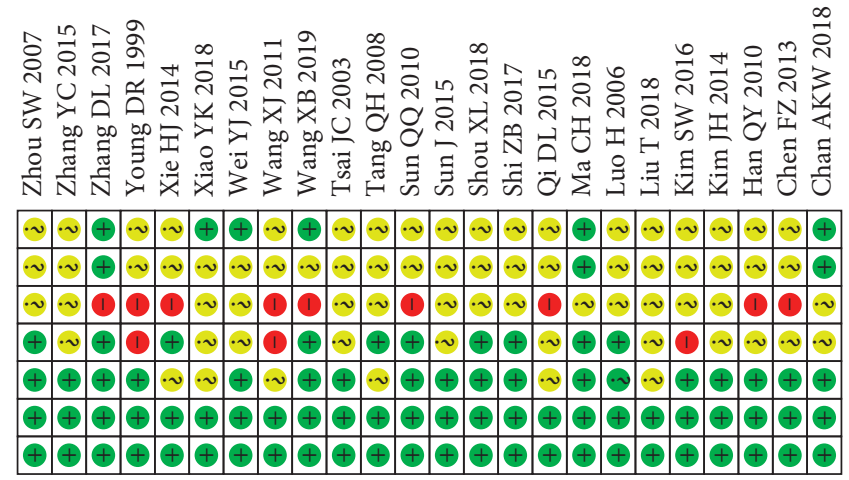

(b)

FiguRE 2: Risk of bias graph. (a) The review authors' judgements about each risk of bias item are presented as percentages across all included studies. The summaries of the risk of bias are included. (b) Review authors' judgements about each risk of bias item for each included study.

SBP

Funnel plot with pseudo 95\% confidence limits

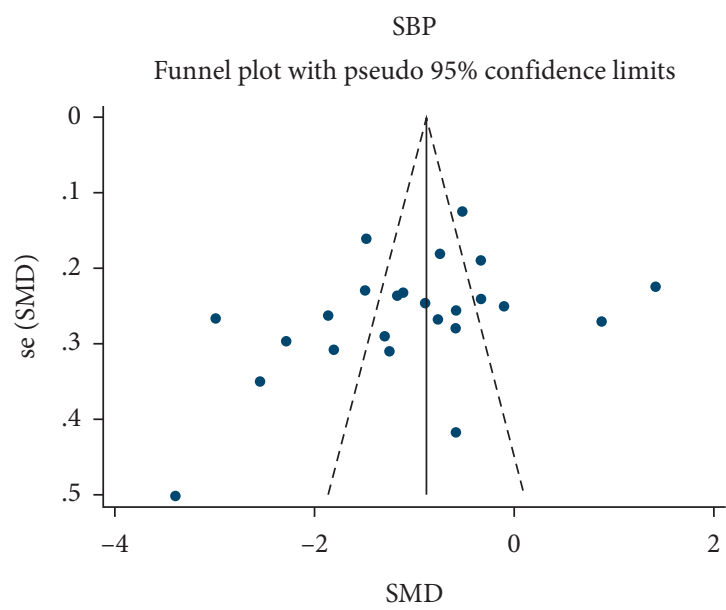

(a)
Random sequence generation (selection bias) Allocation concealment (selection bias)

Blinding of participants and personnel (performance bias)

Blinding of outcome assessment (detection bias)

Incomplete outcome data (attrition bias)

Selective reporting (reporting bias)

Other bias
DBP

Funnel plot with pseudo $95 \%$ confidence limits

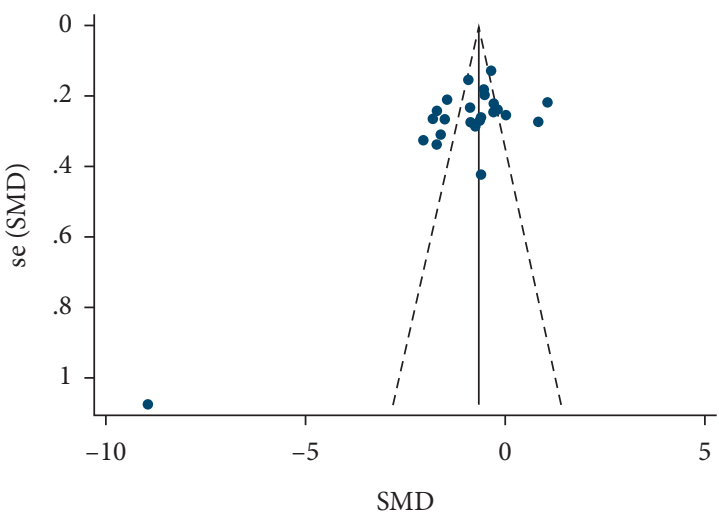

(b)

FIGURE 3: Funnel plot of studies comparing SBP (a) and DBP (b) of the intervention group and control group. SBP, systolic blood pressure; DBP, diastolic blood pressure. 
TABLE 2: Literature publication bias test.

\begin{tabular}{lccccc}
\hline & Coefficient & Standard error & $t$ & $P$ & $95 \%$ CI \\
\hline SBP & -4.181 & 2.756 & -1.52 & 0.143 & $-9.896,1.534$ \\
DBP & -4.755 & 2.144 & -2.22 & 0.037 & $-9.202,-0.308$ \\
\hline
\end{tabular}

SBP, systolic blood pressure; DBP, diastolic blood pressure; CI, confidence intervals.

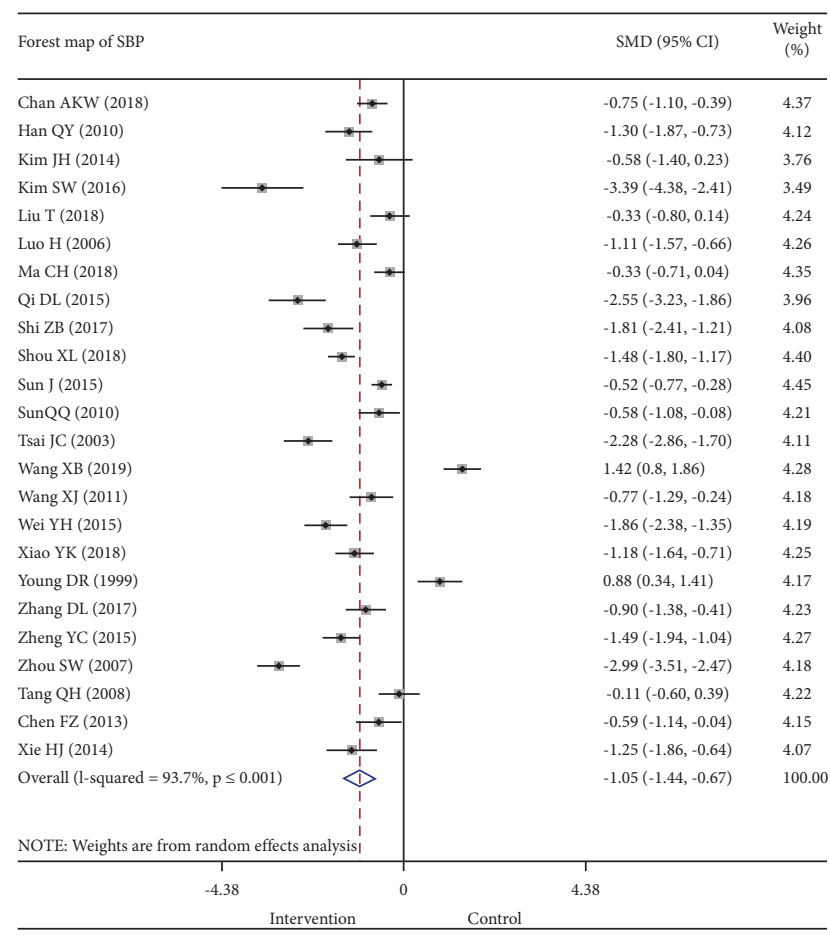

(a)

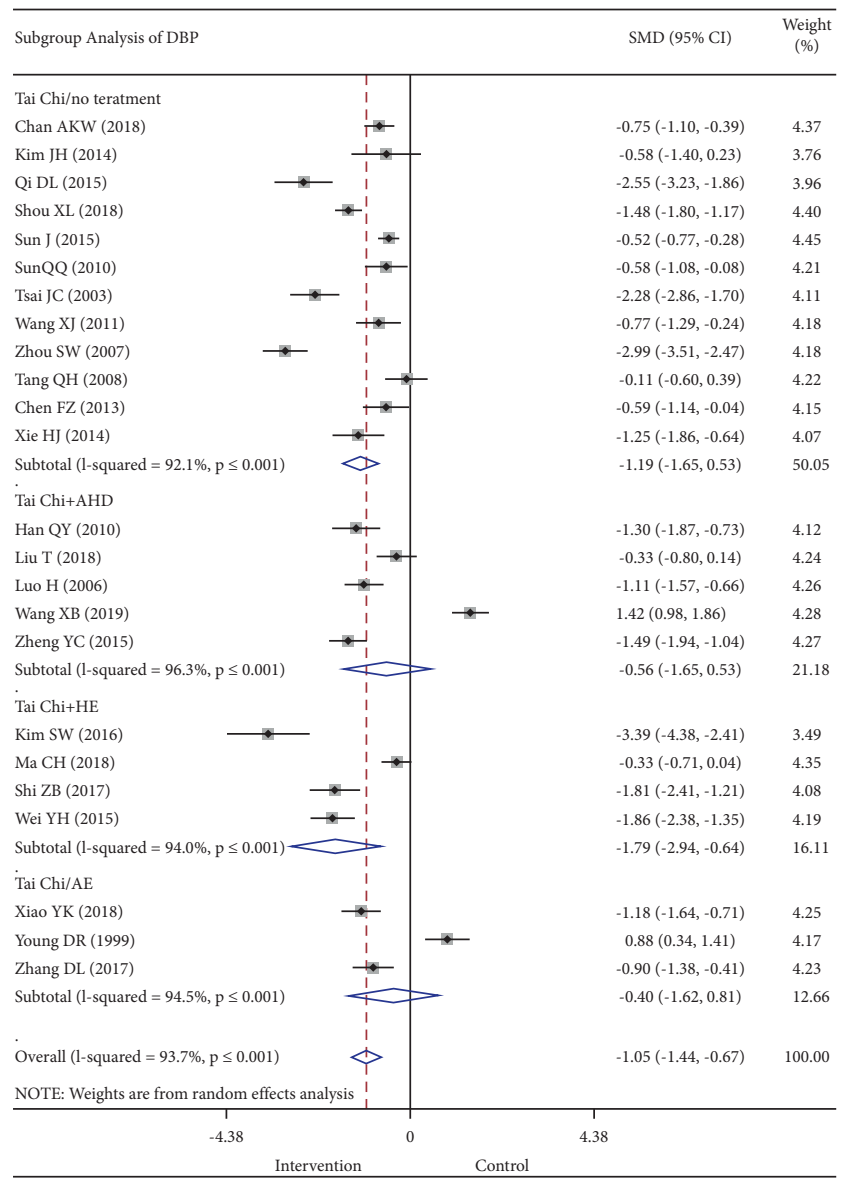

(b)

FIGURE 4: Forest map of all studies (a) and subgroup analysis (b) comparing SBP of the intervention group and the control group. SBP, systolic blood pressure.

remaining studies were combined after removing one study at a time to analyze the impact of individual studies on the combined results. The results of the analysis showed that studies by Zhou [20], Kim [8], and Wang [4] had the greatest impact. Significant heterogeneity $\left(I^{2}>50 \%\right)$ was still present, even after removing these data.

3.3.2. DBP. The meta-analysis performed on the 24 studies using DBP indicators found (Figure 5(a)) that Tai Chi exercise improved DBP in patients with hypertension (SMD -0.91 , 95\% CI -1.24 to $-0.58, P \leq 0.001$; Table 3 ). Furthermore, the improvement in DBP was better in the intervention group than in the control group. Meta-analysis results showed significant heterogeneity, and the discrepancy was statistically significant $\left(I^{2}=91.9 \%, \quad P \leq 0.001\right.$;
Figure 5(a)), which required further discussion on the sources of heterogeneity.

The difference in the effect of Tai Chi on DBP in patients with hypertension may have been affected by the intervention measures; therefore, a subgroup analysis was performed (Figure 5(b)) using the random response mode. The results showed that Tai Chi + AHD intervention had no statistical significance $\left(P=0.253>0.05 ; I^{2}=95.7 \%\right)$, in the Tai Chi group versus the AE group, there is no significant difference in reduction of DBP (SMD $-0.11,95 \%$ CI -1.06 to $\left.0.83, P=0.812>0.05 ; I^{2}=91.5 \%\right)$, and the SMD after intervention with Tai Chi + HE (SMD $-2.86,95 \% \mathrm{CI}-4.42$ to $\left.-1.30, P \leq 0.001 ; I^{2}=96.1 \%\right)$ was higher than that with Tai $\mathrm{Chi}+\mathrm{AHD} \quad(\mathrm{SMD}-0.59, \quad 95 \%$ CI -1.60 to 0.42 , $\left.P=0.253>0.05 ; I^{2}=95.7 \%\right)$ and Tai Chi only (SMD -0.84 , $95 \%$ CI -1.12 to $-0.57, P \leq 0.001 ; I^{2}=78.5 \%$ ) (Table 3 ). 
TABLE 3: Results of meta-analysis and subgroup analysis.

\begin{tabular}{|c|c|c|c|c|c|c|c|c|c|c|c|c|}
\hline & & \multirow{2}{*}{ SBP } & \multirow{2}{*}{ DBP } & \multirow{2}{*}{ BMI } & \multicolumn{8}{|c|}{ QOL } \\
\hline & & & & & $\mathrm{PF}$ & $\mathrm{RP}$ & $\mathrm{GH}$ & BP & VT & SF & $\mathrm{RE}$ & $\mathrm{MH}$ \\
\hline \multirow{6}{*}{$\begin{array}{l}\text { Invention group vs. } \\
\text { control group }\end{array}$} & $I^{2}(\%)$ & 93.7 & 91.9 & 69.4 & 91.3 & 65 & 88.1 & 83.1 & 84.3 & 93.1 & 88.1 & 88.2 \\
\hline & SMD & -1.05 & -0.91 & -0.08 & 0.86 & 0.86 & 0.75 & 0.65 & 0.71 & 0.63 & 0.64 & 0.73 \\
\hline & $95 \%$ & $(-1.44$ & $(-1.24$ & $(-0.35$ & $(0.36$ & $(0.61$ & $(0.32$ & $(0.29$ & $(0.34$ & (0.07, & $(0.22$, & (0.31, \\
\hline & CI & $-0.67)$ & $-0.58)$ & $0.19)$ & 1.37) & 1.11) & 1.17) & $1.00)$ & 1.07) & 1.19) & $1.06)$ & $1.16)$ \\
\hline & $Z$ & 5.39 & 5.35 & 0.59 & 3.38 & 6.67 & 3.44 & 3.56 & 3.75 & 2.21 & 2.96 & 3.36 \\
\hline & $P$ & $\leq 0.001$ & $\leq 0.001$ & 0.554 & 0.001 & $\leq 0.001$ & 0.001 & $\leq 0.001$ & $\leq 0.001$ & 0.027 & 0.003 & 0.001 \\
\hline \multirow{5}{*}{$\begin{array}{l}\text { Tai Chi group vs. no } \\
\text { treatment }\end{array}$} & $I^{2}(\%)$ & 92.1 & 78.5 & NA & NA & NA & NA & NA & NA & NA & NA & NA \\
\hline & SMD & -1.19 & -0.84 & NA & NA & NA & NA & NA & NA & NA & NA & NA \\
\hline & $\begin{array}{c}95 \% \\
\text { CI }\end{array}$ & $\begin{array}{l}(-1.66 \\
-0.72)\end{array}$ & $\begin{array}{c}(-1.12 \\
-0.57)\end{array}$ & NA & NA & NA & NA & NA & NA & NA & NA & NA \\
\hline & $Z$ & 4.98 & 5.99 & NA & NA & NA & NA & NA & NA & NA & NA & NA \\
\hline & $P$ & $\leq 0.001$ & $\leq 0.001$ & NA & NA & NA & NA & NA & NA & NA & NA & NA \\
\hline \multirow{5}{*}{$\begin{array}{l}\text { Tai Chi + AHD } \\
\text { group vs. control } \\
\text { group }\end{array}$} & $I^{2}(\%)$ & 96.3 & 95.7 & NA & NA & NA & NA & NA & NA & NA & NA & NA \\
\hline & SMD & -0.56 & -0.59 & NA & NA & NA & NA & NA & NA & NA & NA & NA \\
\hline & $\begin{array}{c}95 \% \\
\text { CI }\end{array}$ & $\begin{array}{c}(-1.65 \\
0.53)\end{array}$ & $\begin{array}{c}(-1.60 \\
0.42)\end{array}$ & NA & NA & NA & NA & NA & NA & NA & NA & NA \\
\hline & $Z$ & 1.01 & 1.14 & NA & NA & NA & NA & NA & NA & NA & NA & NA \\
\hline & $P$ & 0.314 & 0.253 & NA & NA & NA & NA & NA & NA & NA & NA & NA \\
\hline \multirow{5}{*}{$\begin{array}{l}\text { Tai Chi }+ \text { HE group } \\
\text { vs. control group }\end{array}$} & $I^{2}(\%)$ & 94 & 96.1 & NA & NA & NA & NA & NA & NA & NA & NA & NA \\
\hline & SMD & -1.79 & -2.86 & NA & NA & NA & NA & NA & NA & NA & NA & NA \\
\hline & $\begin{array}{c}95 \% \\
\text { CI }\end{array}$ & $\begin{array}{c}(-2.94 \\
-0.64)\end{array}$ & $\begin{array}{l}(-4.42 \\
-1.30)\end{array}$ & NA & NA & NA & NA & NA & NA & NA & NA & NA \\
\hline & $Z$ & 3.06 & 3.59 & NA & NA & NA & NA & NA & NA & NA & NA & NA \\
\hline & $P$ & 0.002 & $\leq 0.001$ & NA & NA & NA & NA & NA & NA & NA & NA & NA \\
\hline \multirow{5}{*}{$\begin{array}{l}\text { Tai Chi group vs. } \\
\text { AE group }\end{array}$} & $I^{2}(\%)$ & 94.5 & 91.5 & NA & NA & NA & NA & NA & NA & NA & NA & NA \\
\hline & SMD & -0.4 & -0.11 & NA & NA & NA & NA & NA & NA & NA & NA & NA \\
\hline & $\begin{array}{c}95 \% \\
\mathrm{CI}\end{array}$ & $\begin{array}{c}(-1.62 \\
0.81)\end{array}$ & $\begin{array}{c}(-1.06 \\
0.83)\end{array}$ & NA & NA & NA & NA & NA & NA & NA & NA & NA \\
\hline & $Z$ & 0.65 & 0.24 & NA & NA & NA & NA & NA & NA & NA & NA & NA \\
\hline & $P$ & 0.513 & $\leq 0.001$ & NA & NA & NA & NA & NA & NA & NA & NA & NA \\
\hline
\end{tabular}

SBP, systolic blood pressure; DBP, diastolic blood pressure; BMI, body mass index; PF, physical functioning; RP, role-physical; GH, general health; BP, bodily pain; VT, vitality; SF, social functioning; RE, role-emotional; MH, mental health; AHD, antihypertensive drugs; HE, health education; SMD, standard mean.

Multivariate meta-regression analysis was conducted using the research characteristics, such as source of research objects $(t=-0.95, \quad P=0.354>0.05)$, research quality $(t=-0.74, P=0.468>0.05)$, and intervention cycle $(t=-0.5$, $P=0.621>0.05)$, as covariables. The results indicated that the different research characteristics had no significant impact on interstudy heterogeneity (Supplementary Table 3).

Furthermore, an influence analysis of the individual studies was conducted (Supplementary Figure 1B). The remaining studies were combined after removing one study at a time to analyze the impact of individual studies on the combined results. The results of the analysis showed that the study by Kim [8] had the most significant impact. The remaining studies were combined after removing the data, indicating that there was still a high level of heterogeneity $\left(I^{2}>50 \%, P<0.05\right)$.

\subsection{Secondary Outcomes}

3.4.1. BMI. Six studies $[7,10,19,22,25,26]$ reported BMI, and upon meta-analysis, no significant difference in BMI between the intervention and control groups was found
(SMD $-0.08,95 \%$ CI -0.35 to $-0.19, P=0.554$; Table 3 ). The results of the meta-analysis showed that heterogeneity was significant $\left(I^{2}=69.4 \%, P=0.006\right.$; Figure 6).

3.4.2. QOL. Seven studies $[10,17,18,24-27]$ reported this outcome. The 36-Item Short Form Survey was used in all the studies; a higher score indicated a higher QOL. Upon conducting a meta-analysis, the following results were gathered: physical functioning (SMD 0.86, 95\% CI 0.36 to 1.37, $P=0.001 ; I^{2}=91.3 \%$ ), role-physical (SMD 0.86, 95\% CI 0.61 to $1.11, P \leq 0.001 ; I^{2}=65 \%$ ), general health (SMD $0.75,95 \%$ CI 0.32 to $1.17, P=0.001 ; I^{2}=88.1 \%$ ), bodily pain (SMD $0.65,95 \%$ CI 0.29 to $1.00, P \leq 0.001 ; I^{2}=83.1 \%$ ), vitality (SMD $0.71,95 \%$ CI 0.34 to $1.07, P \leq 0.001 ; I^{2}=84.3 \%$ ), social functioning (SMD 0.63, 95\% CI 0.07 to 1.19 , $P=0.027 ; I^{2}=93.1 \%$ ), role emotional (SMD 0.64, 95\% CI 0.22 to $1.06, P=0.003 ; I^{2}=88.1 \%$ ), and mental health (SMD $0.73,95 \%$ CI 0.31 to $1.16, P=0.001 ; I^{2}=88.2 \%$ ) (Table 3). So, the meta-analysis found that the intervention effect on QOL in patients with hypertension in the intervention group was better than that in the control group (Figure 7). In addition, the heterogeneity was significant, and the difference was statistically significant. We performed an influence analysis 


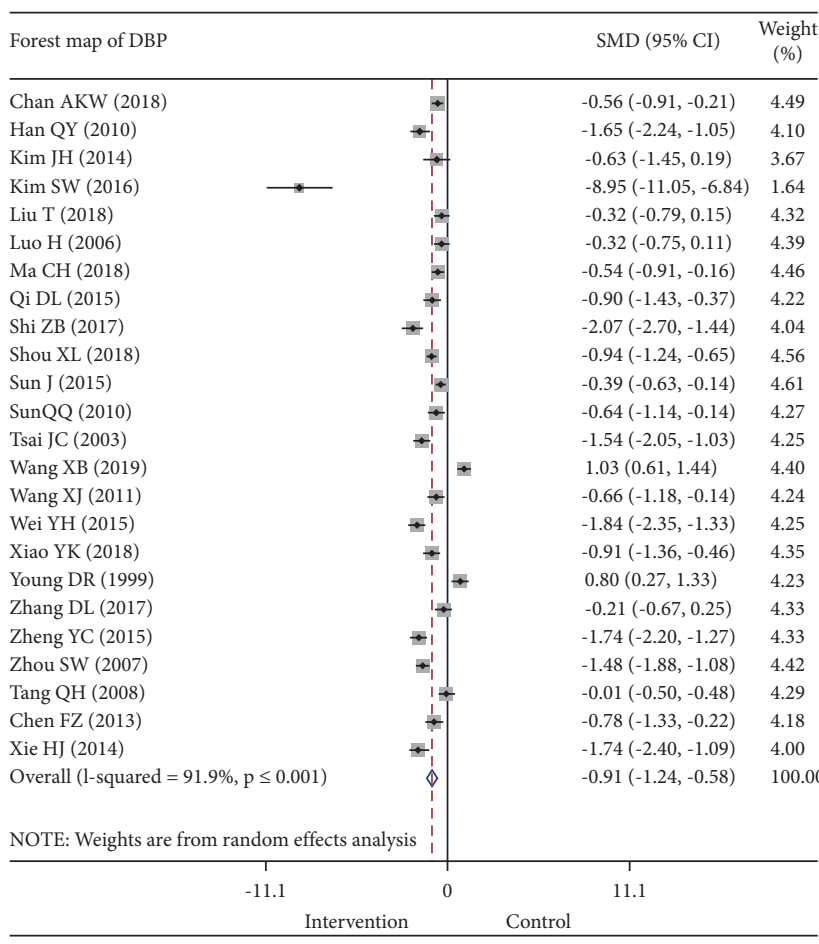

(a)

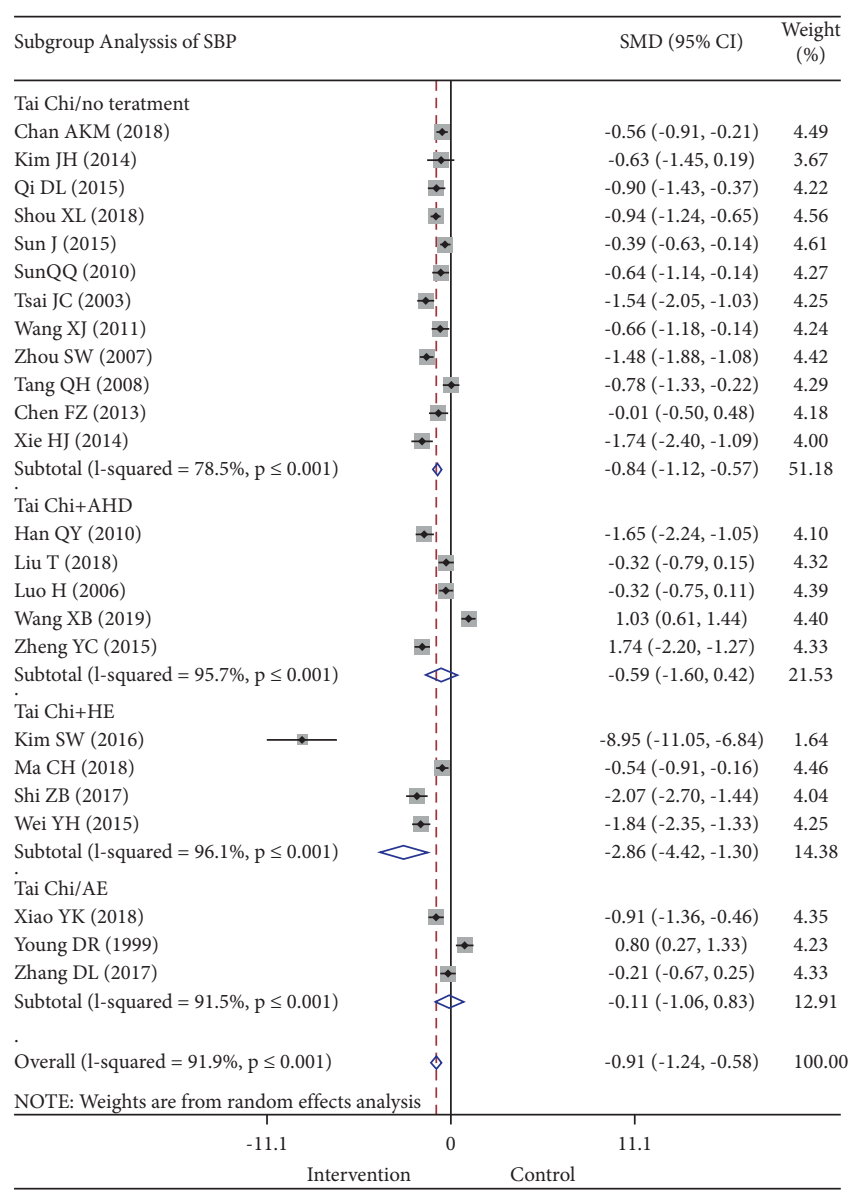

(b)

FIGURE 5: Forest map of all studies (a) and subgroup analysis (b) comparing DBP of the intervention group and the control group. DBP, diastolic blood pressure.

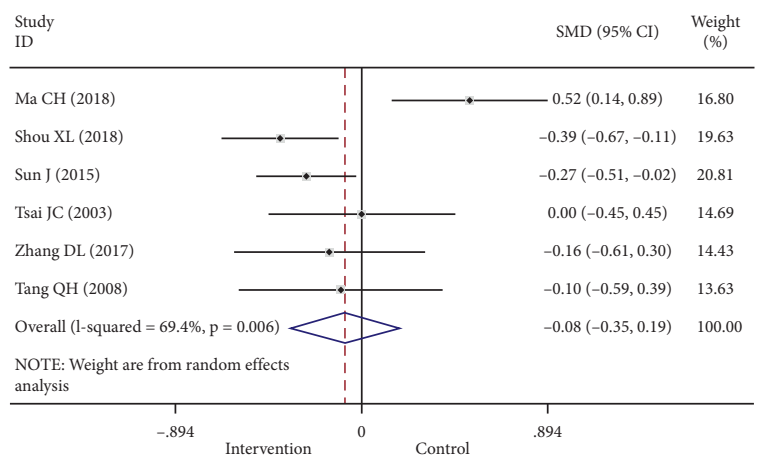

FIGURE 6: Forest map of studies comparing BMI of the intervention group and control group. BMI, body mass index.

to explore potential sources of heterogeneity (Supplementary Figure 2), but the results did not change substantially.

\section{Discussion}

4.1. Summary of Findings. We included 24 RCTs $(2,095$ patients) in this meta-analysis, with two $[4,23]$ reporting Tai Chi's lack of antihypertensive effects. The meta-analysis found that the improvement in SBP and DBP among patients with hypertension in the intervention group was better than that seen in the control group, and the former also had improved QOL. However, Tai Chi intervention did not improve BMI.

4.2. Added Value to Previous Meta-Analysis on the Same Topic. There have been six previous systematic reviews [31-36] examining the effects of Tai Chi on hypertension. The reasons for our update were as follows: first, we focused on the influence of duration of exercise on the results. According to a meta-analysis by Zhang [32], if the exercise duration was less than three weeks, Tai Chi would not significantly reduce DBP. As such, we only included studies that had at least three weeks of intervention. Second, there was an issue of whether the effects of Tai Chi on blood pressure was applicable to different ethnicities. At the same time, we found that all patients included in the previous meta-analysis were from China. Therefore, we conducted a comprehensive search and found two articles from South Korea $[8,13]$ and one from Baltimore, USA [23]. We only included RCTs to avoid having incorrect results due to the inclusion of non-RCTs or incomplete data. Third, we found 


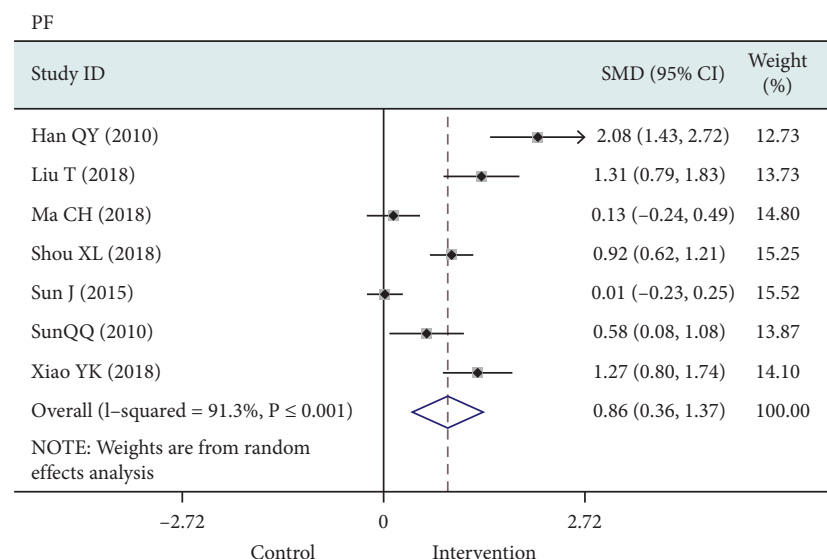

(a)

\begin{tabular}{l} 
GH \\
\hline Study ID \\
\hline Han QY (2010) \\
Liu T (2018) \\
Ma CH (2018) \\
Shou XL (2018) \\
Sun J (2015) \\
SunQQ (2010) \\
Xiao YK (2018) \\
Overall (1-squared = 88.1\%, P $\leq 0.001)$ \\
NOTE: Weights are from random \\
effects analysis
\end{tabular}

(c)

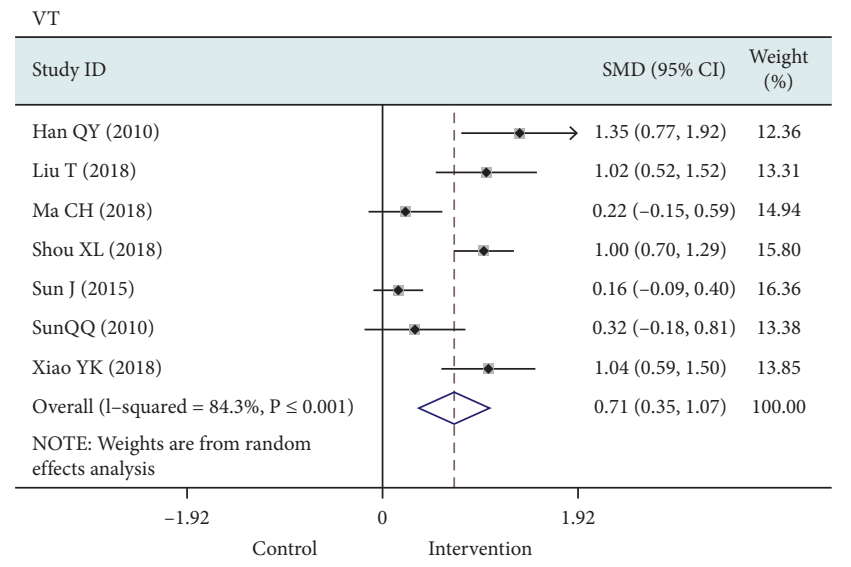

(e)

\begin{tabular}{l} 
RP \\
\hline Study ID \\
\hline Han QY (2010) \\
Liu T (2018) \\
Ma CH (2018) \\
Shou XL (2018) \\
Sun J (2015)
\end{tabular}

(b)

\begin{tabular}{|c|c|c|c|}
\hline \multicolumn{2}{|l|}{ Study ID } & \multirow{2}{*}{$\begin{array}{c}\operatorname{SMD}(95 \% \mathrm{CI}) \\
161(1.02,2.21)\end{array}$} & \multirow{2}{*}{$\begin{array}{c}\begin{array}{c}\text { Weight } \\
(\%)\end{array} \\
11.93\end{array}$} \\
\hline Han QY (2010) & $\longrightarrow$ & & \\
\hline Liu T (2018) & $\longrightarrow$ & $1.34(0.82,1.86)$ & 12.96 \\
\hline Ma CH (2018) & & $0.24(-0.13,0.61)$ & 15.01 \\
\hline Shou XL (2018) & & $0.78(0.49,1.07)$ & 16.03 \\
\hline Sun J (2015) & $\rightarrow$ & $0.44(0.20,0.68)$ & 16.54 \\
\hline SunQQ (2010) & $\rightarrow$ & $0.43(-0.07,0.92)$ & 13.30 \\
\hline Xiao YK (2018) & - & $-0.08(-0.51,0.35)$ & 14.23 \\
\hline Overall $(1-$ squared $=83.1 \%, \mathrm{P} \leq 0.001)$ & $<$ & $0.65(0.29,1.00)$ & 100.00 \\
\hline $\begin{array}{l}\text { NOTE: Weights are from random } \\
\text { effects analysis }\end{array}$ & & & \\
\hline-2.21 & 2.2 & & \\
\hline
\end{tabular}

(d)

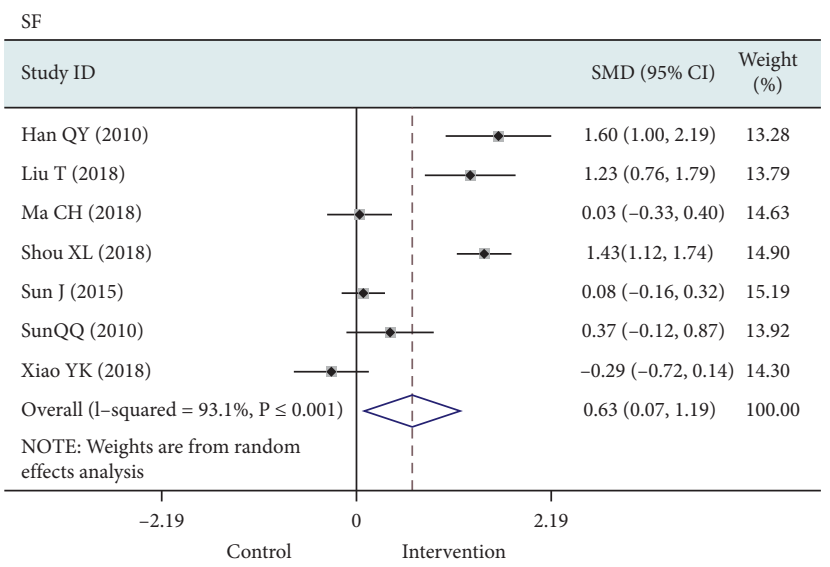

(f)

FIgURe 7: Continued. 


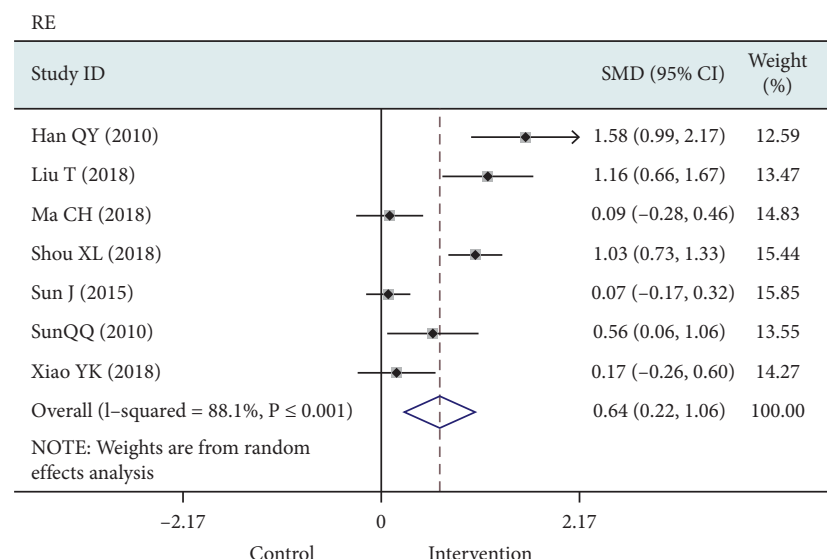

(g)

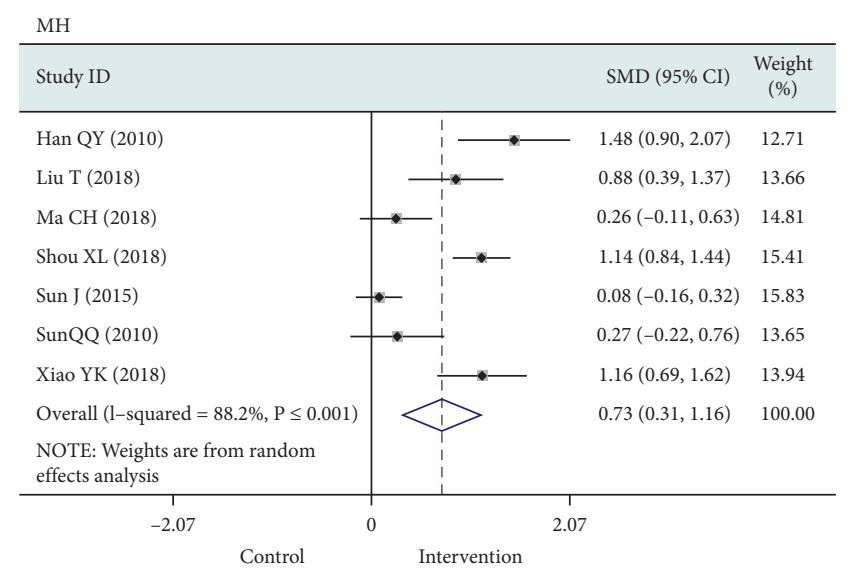

(h)

FIgURE 7: Forest map of the studies comparing PF (a), RP (b), GH (c), BP (d), VT (e), ST (f), RE (g), and MH (h) scores of the intervention group and control group. VT, vitality; SF, social functioning; RE, role-emotional; MH, mental health; PF, physical functioning; RP, role limitations due to physical health; $\mathrm{BP}$, bodily pain; $\mathrm{GH}$, general health perceptions.

that in some studies, the medications, combined with Tai Chi, were not gradually reduced despite the increase in Tai Chi exercise; this could profoundly influence Tai Chi's effect on blood pressure. However, the previous meta-analyses were not mindful of this, so we conducted a subgroup analysis of different interventions. Fourth, most of the studies only performed a meta-analysis using blood pressure as an outcome, but we found that other secondary indicators, such as QOL, may explain the mechanism underlying Tai Chi's effect on blood pressure. Therefore, secondary indexes, such as BMI, WC, and QOL, were added to the data collection.

\subsection{Interpretation of the Results}

4.3.1. SBP and DBP. The meta-analysis results showed that Tai Chi intervention could significantly improve SBP and DBP in patients with hypertension. Tai Chi reduces blood pressure through various means. First, during Tai Chi exercise, the amount of sodium lost may exceed the regular intake level, leading to an improvement in blood pressure [22]. Second, after exercise, Tai Chi practitioners had higher plasma levels of NO metabolites than sedentary and sedentary participants did [37]. Furthermore, as an endothelium-dependent vasodilator, NO plays a significant role in regulating vascular tension [38]. NO can also reduce skin vascular resistance, thereby reducing hypertension. Third, NLRP3 inflammasome damages endothelial cells, and exercise reduces the expression of NLRP3 inflammasome components, thereby lowering blood pressure [39, 40]. Fourth, performing Tai Chi can cultivate the mind, edify sentiments, make people broad-minded, open-minded, and optimistic, and eliminate the effects of bad mood on the nervous system caused by changes in blood pressure [41].

We performed a subgroup analysis of different interventions. Tai Chi intervention alone was used in twelve of the included articles, and the results showed that Tai Chi intervention alone could dramatically improve SBP and DBP in patients with essential hypertension. However, the subgroup analysis results of Tai Chi combined with conventional Western medicines showed no statistic significant changes, which do not automatically indicate that Tai Chi has no antihypertensive effect. This result may have been due to the simultaneous use of Tai Chi and drugs, complicating the study and making it difficult to distinguish the effects of the two interventions. If the drugs were gradually increased or decreased after the Tai Chi intervention and the changes in blood pressure were recorded simultaneously, the effect of Tai Chi intervention on prehypertension could be understood, and the complexity of the intervention could be reduced to obtain more accurate results. There are two methods to reduce this complexity in the intervention and obtain more accurate results. First, after the Tai Chi intervention, the gradual increase or decrease in the dose of drugs should be noted while observing the changes in blood pressure. Second, we can study the intervention effect of Tai Chi on prehypertension, that is, the intervention of people with high normal blood pressure who has not taken medicine, so as to observe the influence of Tai Chi on blood pressure. In addition, the subgroup analysis of Tai Chi combined with HE showed that the antihypertensive effect was greater than that with Tai Chi intervention alone, possibly because $\mathrm{HE}$ includes dietary, exercise, lifestyle changes, and stress reduction, all of which may enhance the effect of blood pressure reduction.

The subgroup analysis showed that Tai Chi presents no significant antihypertensive effects on SBP and DBP compared with AE. At present, professional organizations recommend $\mathrm{AE}$ as the primary mode of exercise to prevent and treat hypertension [42]. However, very few adults with high blood pressure follow this recommendation [43]. In the 60-69 years age group, a reduction of $10 \mathrm{mmHg}$ in SBP and $5 \mathrm{mmHg}$ in DBP was associated with a $22 \%$ and $41 \%$ decrease in the risk of heart disease and stroke, respectively [44]. Patients of this age are more suited to do Tai Chi than $\mathrm{AE}$ for physical reasons. Therefore, it can be used as a 
substitute for under certain conditions, such as when people are unable or unwilling to perform AE.

4.3.2. QOL. The results of the meta-analysis showed that Tai Chi could improve the QOL of patients with hypertension as it strengthens the body and improves the mind. With improved mental and physical control, people's motivation to continue to exercise increases, as does their overall well-being [45]. Increased circulating levels of $\beta$-endorphins, which are associated with chronic pain, are potential biomarkers of endogenous opioid analgesic power [46]. Compared to light exercise, Tai Chi reduces plasma $\beta$-endorphin levels more efficiently, thereby reducing chronic pain [47]. It can also help patients overcome their fear of pain and improve their psychosocial health status and confidence [48].

Elderly individuals are prone to falls, one of the main risk factors for poor QOL. The probability of falling increases with age. Worldwide, the annual incidence of falls is around $30-40 \%$ among people over 65 years of age but increases to $50 \%$ among people 80 years of age and over [49]. Tai Chi exercise for elderly individuals helps prevent falls, with increased frequency of Tai Chi exercise being associated with reduced frequency of falls [50]. Furthermore, people with fibromyalgia may also benefit from Tai Chi exercise [51]. Overall, by regulating their body and mind, Tai Chi can improve people's mood, pain, and general health, thus improving their QOL.

4.4. Limitation. This study had the following limitations: (1) the heterogeneity was high among selected trials. There are some additional unidentified moderators existing in included studies which may cause considerable heterogeneity, such as the intensity of Tai Chi practice, the intervention duration, and the frequency of Tai Chi training. (2) Only two of the 24 included studies mentioned blinding methods. For evaluators, which may lead to deception and performance bias. (3) The number of samples in one article was negligible. (4) The studies also did not adequately report the patients' medical adherence and the teaching ability of the coach. Therefore, we should maintain a conservative attitude towards interpretation of the results that imply meaningful reduction of hypertension caused by Tai Chi.

4.5. Conclusion. The results show that Tai Chi exercise can effectively improve SBP, DBP, and QOL among patients with hypertension. As such, it should be promoted as a safe and effective adjuvant therapy for hypertension. The results of this study can be used as a theoretical basis for guiding clinical practice. Nevertheless, because of the substantial interstudy heterogeneity and the influence of publication bias, these findings still need to be verified by a rigorously designed study with a large sample size.

\section{Data Availability}

The manuscript is a meta-analysis. With a time limit of December 5, 2020, we searched for RCTs in five English and two Chinese databases (Web of Science, PubMed, Korea Citation Index, EMBASE, the Cochrane Library, China National Knowledge Infrastructure, and Wanfang Data). We searched for terms related to Tai Chi and hypertension. Overall, the data of 2,095 patients from 24 RCTs (Young et al., 1999; Tsai et al., 2003; Luo, 2006; Zhou, 2007; Tang, 2008; Qiao-ying et al., 2010; Sun, 2010; Wang et al., 2011; Chen and Lu, 2013; Kim, 2014; Xie and Bai, 2014; Qi et al., 2015; Sun and Buys, 2015; Wei et al., 2015; Zheng et al., 2015; Kim et al., 2016; Shi and Miao, 2017; Zhang, 2017; Chan et al., 2018; Liu et al., 2018; Ma et al., 2018; Shou et al., 2018; Xiao, 2018; and Wang and Ye, 2019) were obtained, as given in Table 1 and Supplementary Table 1 in the manuscript.

\section{Conflicts of Interest}

The authors declare that they have no conflicts of interest.

\section{Authors' Contributions}

XDP, YHG, and YWX provided ideas for research and drafted the manuscript. XYL, XDP, LT, JHS, XL, FY, YFX, and XS searched scientific literatures, collected data, and analyzed the data. The results were analyzed by XDP, NA, $\mathrm{CL}$, and YWX. All the authors commented on the manuscript. Xiandu Pan, Li Tian, Fan Yang, and Jiahao Sun contributed equally to this work.

\section{Acknowledgments}

This work was supported by the National Key R \& D Program of China (2018YFC1704901 and 2018YFC1704900) and CACMS Innovation Fund (CI2021A00919).

\section{Supplementary Materials}

Supplementary Table 1 . The difference in values before and after intervention. SBP, systolic blood pressure; DBP, diastolic blood pressure; BMI, body mass index; WC, waist circumference; NO, nitric oxide content; QOL, quality of life; PF, physical functioning; RP, role limitations due to physical health; BP, bodily pain; GH, general health perceptions; VT, vitality; SF, social functioning; RE, role limitations due to emotional problems; $\mathrm{MH}$, mental health; I, intervention group; C, control group. Supplementary Table 2. Multivariate meta-regression analysis of studies evaluating systolic blood pressure in patients with hypertension doing Tai Chi. Coef, coefficient; Std.Err, standard error; CI, confidence intervals. Supplementary Table 3. Multivariate meta-regression analysis of studies evaluating diastolic blood pressure in patients with hypertension doing Tai Chi. Coef, coefficient; Std.Err, standard error; CI, confidence intervals. Supplementary Figure 1. Influence analysis of studies assessing SBP (A) and DBP (B) in patients with hypertension by Tai Chi. SBP, systolic blood pressure; DBP, diastolic blood pressure. Supplementary Figure 2. Influence analysis of studies assessing PF (A), RP (B), GH (C), BP (D), VT (E), ST (F), RE (G), and MH (H) scores in patients with hypertension by Tai Chi. VT, vitality; SF, social functioning; $\mathrm{RE}$, role limitations due to emotional problems; $\mathrm{MH}$, mental 
health; PF, physical functioning; RP, role limitations due to physical health; BP, bodily pain; GH, general health perceptions. (Supplementary Materials)

\section{References}

[1] M. H. Forouzanfar, P. Liu, G. A. Roth et al., "Global burden of hypertension and systolic blood pressure of at least 110 to 115 mm Hg, 1990-2015," Jama, vol. 317, no. 2, pp. 165-182, 2017.

[2] J. D. Stanaway, A. Afshin, E. Gakidou, S. S. Lim, D. Abate, and K. H. Abate, "Global, regional, and national comparative risk assessment of 84 behavioural, environmental and occupational, and metabolic risks or clusters of risks for 195 countries and territories, 1990-2017: a systematic analysis for the Global Burden of Disease Study 2017," Lancet, vol. 392, no. 10159, pp. 1923-1994, 2018.

[3] R. Xiaomeng, L. Yanda, Y. Xinyu et al., "The effects of tai chi training in patients with heart failure: a systematic review and meta-analysis," Frontiers in Physiology, vol. 8, p. 989, 2017.

[4] X. B. Wang and L. P. Ye, "Effect of 24-type simplified taijiquan on primary hypertension with mild anxiety in the elderly," Fujian University of Traditional Chinese Medicine, vol. 50, no. 4, pp. 73-75, 2019.

[5] A. W. K. Chan, S. Y. Chair, D. T. F. Lee et al., "Tai Chi exercise is more effective than brisk walking in reducing cardiovascular disease risk factors among adults with hypertension: a randomised controlled trial," International Journal of Nursing Studies, vol. 88, pp. 44-52, 2018.

[6] Z. B. Shi and Z. L. Miao, "Study on the treatment of grade 1 hypertension by traditional Chinese medicine physical therapy," China Manipulation Qi Gong Therapy, vol. 8, no. 20, pp. 51-52, 2017.

[7] D. L. Zhang, A Clinical study:Effecct of 24 Movement Form of Tai Chi on Senile Patients with Essential Hypertension, Chengdu University of TCM, Chengdu, China, 2017.

[8] S. W. Sungwoon Kim, H. C. Kimhancheol, and W. C. Kim, "The long-term effect of Tai chi exercise on blood pressure, heart rate, and lipid profile in older women with hypertension," Journal of Adapted Physical Activity and Exercise, vol. 24, no. 4, pp. 35-45, 2016.

[9] D. L. Qi, Y. M. Li, and X. H. Yan, "Influence of eight forms tai chi on blood pressure levels of hypertension patients," Sichuan Sports Science, vol. 34, no. 5, pp. 24-26, 2015.

[10] J. Sun and N. Buys, "Community-based mind-body meditative tai chi Program and its effects on improvement of blood pressure, weight, renal function, serum lipoprotein, and quality of life in Chinese adults with hypertension," The American Journal of Cardiology, vol. 116, no. 7, pp. 1076-1081, 2015.

[11] Y. H. Wei, J. Y. Chen, and X. Y. Lu, "Influence of companion exercise tai chi on blood pressure control in elder with hypertension," Rehabilitation Nursing Journal, vol. 14, no. 8, pp. 752-753, 2015.

[12] Y. C. Zheng, L. Chen, and J. Q. Yang, "Tai chi systematic review of primary effects on blood pressure and quality of life patients of hypertension," Journal of Liaoning University (Natural Sciences Edition), vol. 17, no. 4, pp. 143-146, 2015.

[13] J. H. Kim, Jeong-Ha, "The effect of tai chi chuan training on the automatic cardiac nerve activity and blood pressure in elderly women with hypertension," Official Journal of the Koeran Society of Dance Science, vol. 31, no. 1, pp. 157-168, 2014.
[14] H. J. Xie and C. Q. Bai, "Gaseous signal molecular mechanism of tai chi's intervention in aged essential hypertension," Journal of Wuhan Institute of Physical Education, vol. 48, no. 2, pp. 51-54, 2014.

[15] F. Z. Chen and Q. B. Lu, "Influence of tai chi to hypertensive blood pressure," Today Nurse, vol. 4, pp. 18-19, 2013.

[16] X. J. Wang, Z. K. Jing, and N. N. Zheng, "Effects of tai chi exercises of various intensities on essential hypertension," Journal of Shenyang Sport University, vol. 30, no. 04, pp. 82-85, 2011.

[17] Q. Y. Han, X. F. Huang, L. Lei, and L. Q. Chen, "The effect of shadow boxing exercise on the long-term quality of life in middle-aged and elderly patients," Chinese Journal of Integrative Medicine, vol. 14, pp. 1617-1619, 2010.

[18] Q. Q. Sun, Research on the Effect of Middle-Aging and Elderly High Blood Pressure Patients' Quality of Life by Practice Tai Chi, Beijing Sport University, Beijing, China, 2010.

[19] Q. H. Tang, "Observation and study of the figure and physical function and fitness of elder intellectuals by tai chi," Hunan Institute of Science and Technology, vol. 01, pp. 87-90, 2008.

[20] S. W. Zhou, "Effects of Tai chi on blood pressure and lipid profile in patients with stage I essential hypertension," Intel Health Guide News, vol. 15, pp. 60-64, 2007.

[21] H. Luo, "Clinical research of tai chi combined with drugs for essential hypertension," Chinese Medicine, vol. 33, pp. 43-44, 2006.

[22] J.-C. Tsai, W.-H. Wang, P. Chan et al., "The beneficial effects of Tai Chi Chuan on blood pressure and lipid profile and anxiety status in a randomized controlled trial," Journal of Alternative \& Complementary Medicine, vol. 9, no. 5, pp. 747-754, 2003.

[23] D. R. Young, L. J. Appel, S. Jee, and E. R. Miller 3rd., "The effects of aerobic exercise and T'ai Chi on blood pressure in older people: results of a randomized trial," Journal of the American Geriatrics Society, vol. 47, no. 3, pp. 277-284, 1999.

[24] T. Liu, Q. D. Huang, and W. Z. Liu, "Effects of taijiquan on blood pressure, hemorheology and long-term quality of life in elderly patients with hypertension," Chinese Journal of Gerontology, vol. 38, no. 6, pp. 1396-1398, 2018.

[25] C. Ma, W. Zhou, Q. Tang, and S. Huang, "The impact of group-based Tai chi on health-status outcomes among community-dwelling older adults with hypertension," Heart and Lung, vol. 47, no. 4, pp. 337-344, 2018.

[26] X. L. Shou, L. Wang, X. Q. Jin, L. Y. Zhu, A. H. Ren, and Q. N. Wang, "Effect of t'ai chi exercise on hypertension in young and middle-aged in-service staff," Journal of Alternative and Complementary Medicine, vol. 25pp. 73-78, New York, NY), 2018.

[27] Y. K. Xiao, "Effects of eight movement form of tai chi exercises on blood pressure, vascular endothelial function and quality of life in patients with essential hypertension," Chinese Journal of Gerontology, vol. 38, no. 10, pp. 2403-2405, 2018.

[28] Writing group of 2010, "Chinese guidelines for the management of hypertension. "2010 Chinese guidelines for the management of hypertension," Chinese Journal of Cardiology, vol. 39, pp. 579-616, 2011.

[29] J. Chalmers, "The 1999 WHO-ISH guidelines for the management of hypertension," Medical Journal of Australia, vol. 171, no. 9, pp. 458-459, 1999.

[30] J. P. T. T. J. Higgins, J. Chandler, M. Cumpston, T. Li, M. J. Page, and V. A. Welch, Cochrane Handbook for Systematic Reviews of Interventions version 6.1, Cochrane, London, UK, 2020. 
[31] J. Wang, B. Feng, X. Yang et al., "Tai chi for essential hypertension," Evidence-Based Complementary and Alternative Medicine, vol. 2013, Article ID 215254, 10 pages, 2013.

[32] M. J. Zhang and X. Q. Ye, "Effects of TaiChi exercise on blood pressure of middle aged and elderly people: a meta-analysis," Fujian Sports Science and Technology, vol. 34, no. 03, pp. 46-49, 2015.

[33] L. Cai and X. Li, "Meta-analysis of curative effect of Tai Chi on primary hypertension," Clinical Trials of Traditional Chinese Medicines, vol. 28, no. 10, pp. 1425-1428, 2016.

[34] Z. Lian, L. Yang, Y. Bian et al., "Effects of Tai chi on adults with essential hypertension in China: a systematic review and meta-analysis," European Journal of Integrative Medicine, vol. 12, 2017.

[35] C. J. Jin, Z. Y. Zhang, and C. Xie, "Meta-analysis for the effect of tai chi on blood pressure in patients with primary hypertension," Modulation Preview, vol. 45, no. 18, pp. 3446-3451, 2018.

[36] Y. P. Zhang, F. Tao, J. Y. Yang, Z. J. Jia, and C. Y. Wei, "Systematic evaluation and meta-analysis of the antihypertensive effect of Tai chi on patients with essential hypertension," Sport Science, vol. 40, no. 01, pp. 96-104, 2019.

[37] J.-S. Wang, C. Lan, and M.-K. Wong, "Tai Chi Chuan training to enhance microcirculatory function in healthy elderly men," Archives of Physical Medicine and Rehabilitation, vol. 82, no. 9, pp. 1176-1180, 2001.

[38] R. M. J. Palmer, A. G. Ferrige, and S. Moncada, "Nitric oxide release accounts for the biological activity of endotheliumderived relaxing factor," Nature, vol. 327, no. 6122, pp. 524-526, 1987

[39] N. An, Y. Gao, Z. Si et al., "Regulatory mechanisms of the NLRP3 inflammasome, a novel immune-inflammatory marker in cardiovascular diseases," Frontiers in Immunology, vol. 10, p. 1592, 2019.

[40] W. Yang, L. Liu, Y. Wei et al., "Exercise suppresses NLRP3 inflammasome activation in mice with diet-induced NASH: a plausible role of adropin," Laboratory Investigation, vol. 101, no. 3, pp. 369-380, 2020.

[41] P. P. Fu and H. B. Zhang, "Research progress of Ba Duan Jin and Tai Chi in the treatment of essential hypertension and its antihypertensive mechanism," Hebei Journal (TCM), vol. 35, no. 10, pp. 1585-1587, 2013.

[42] L. S. Pescatello, H. V. MacDonald, G. I. Ash et al., "Assessing the existing professional exercise recommendations for hypertension: a review and recommendations for future research priorities," Mayo Clinic Proceedings, vol. 90, no. 6, pp. 801-812, 2015.

[43] US Department of Health and Human Services, Health, and, Human, Services. Topics \& Objectives - Physical Activity, Healthy People, 2020.

[44] M. R. Law, J. K. Morris, and N. J. Wald, "Use of blood pressure lowering drugs in the prevention of cardiovascular disease: meta-analysis of 147 randomised trials in the context of expectations from prospective epidemiological studies," BMJ, vol. 338, no. may19 1, p. b1665, 2009.

[45] C. Lan, S.-Y. Chen, M.-K. Wong, and J.-S. Lai, "Tai Chi training for patients with coronary heart disease," Medicine and Sport Science, vol. 52, pp. 182-194, 2008.

[46] M. Spetea, "Opioid receptors and their ligands in the musculoskeletal system and relevance for pain control," Current Pharmaceutical Design, vol. 19, no. 42, pp. 7382-7390, 2013.

[47] T. You, E. F. Ogawa, S. Thapa et al., "Effects of Tai Chi on beta endorphin and inflammatory markers in older adults with chronic pain: an exploratory study," Aging Clinical and Experimental Research, vol. 32, no. 7, pp. 1389-1392, 2020.
[48] C. Wang, R. Bannuru, J. Ramel, B. Kupelnick, T. Scott, and C. H. Schmid, "Tai Chi on psychological well-being: systematic review and meta-analysis," BMC Complementary and Alternative Medicine, vol. 10, no. 1, p. 23, 2010.

[49] L. Z. Rubenstein and K. R. Josephson, "The epidemiology of falls and syncope," Clinics in Geriatric Medicine, vol. 18, no. 2, pp. 141-158, 2002.

[50] Z.-G. Huang, Y.-H. Feng, Y.-H. Li, and C.-S. Lv, "Systematic review and meta-analysis: tai Chi for preventing falls in older adults," BMJ Open, vol. 7, no. 2, Article ID e013661, 2017.

[51] M. Zhou, D. Zhou, and L. He, "A randomized trial of tai chi for fibromyalgia," New England Journal of Medicine, vol. 363, no. 23 , pp. 2265-2267, 2010. 